\title{
MECHANICAL PROPERTIES OF RICE STRAW AND RICE STRAИ GLASS FIBER REINFORCED EPOXY COMPOSITES
}

Soliman S. Ali-Eldin

\begin{abstract}
Rice straw causes many environmental problems in different world countries. In Egypt, every year, rice str severe environmental pollution in terms of black clouds caused by burning process. In this study, Egyptian was used as a reinforcement material in polymer composites. Rice-straw/epoxy [RS/E] and glass-fiber/ric $\epsilon$ hybrid [G/RS/E] composites were studied. Pure epoxy [E] and glass-fiber/epoxy [G/E] specimens were als for comparison purpose. Composite plates were fabricated by hand lay-up technique in a mold and cured pressure for $24 \mathrm{hr}$, followed by curing at room temperature for 21 days. All composites plates were made $\checkmark$ weight of 960 grams and dimension of $400 \times 400 \mathrm{~mm}$ with different thickness by varying the weight fractic constituent materials. Tensile strength, tensile modulus, bending strength, bending modulus and compress were determined experimentally. Failure modes of all specimens were investigated.
\end{abstract}

